\title{
Lamina-Specific Synaptic Activation Causes Domain-Specific Alterations in Dendritic Immunostaining for MAP2 and CAM Kinase II
}

\author{
Oswald Steward ${ }^{1}$ and Shelley Halpain ${ }^{2}$ \\ ${ }^{1}$ Department of Neuroscience, University of Virginia, Charlottesville, Virginia 22908, and 2Department of Cell Biology, The \\ Scripps Research Institute, La Jolla, California 92037
}

\begin{abstract}
Polyribosomal complexes are selectively localized beneath postsynaptic sites on neuronal dendrites; this localization suggests that the translation of the mRNAs that are present in dendrites may be regulated by synaptic activity. The present study tests this hypothesis by evaluating whether synaptic activation alters the immunostaining pattern for two proteins whose mRNAs are present in dendrites: the dendrite-specific cytoskeletal protein MAP2 and the $\alpha$-subunit of CAMKII. Highfrequency stimulation of the perforant path projections to the dentate gyrus, which terminate in a discrete band on the dendrites of dentate granule cells, produced a two-stage alteration in immunostaining for MAP2 in the dendritic laminae. Five minutes of stimulation (30 trains) caused a decrease in MAP2 immunostaining in the lamina in which the activated synapses terminate. After more prolonged periods of stimulation (1-2 hr),
\end{abstract}

there was an increase in immunostaining in the sideband laminae just proximal and distal to the activated band of synapses. The same stimulation paradigm produced a modest increase in immunostaining for $\alpha$-CAMKII in the activated laminae, with no detectable changes in the sideband laminae. The alterations in immunostaining for MAP2 were diminished, but not eliminated, by inhibiting protein synthesis; the increases in CAMKII were not. These findings reveal that patterned synaptic activity can produce domain-specific alterations in the molecular composition of dendrites; these alterations may be caused in part by local protein synthesis and in part by other mechanisms.

Key words: dendritic mRNA; MAP2; calcium-calmodulindependent protein kinase II; synapse; protein synthesis; protein synthesis inhibitors; LTP
An important aspect of neuronal gene expression is that certain mRNAs are translated locally at synapses. This idea was based on the discovery of synapse-associated polyribosome complexes (SPRCs), polyribosomes that are localized beneath synaptic sites on dendrites (Steward and Levy, 1982; Steward, 1983; Steward and Fass, 1983). Subsequent studies revealed that a select subset of mRNAs is present in dendrites, providing a substrate for local synthesis of the respective proteins (Steward et al., 1996a,b).

The selective localization of SPRCs in the subsynaptic cytoplasm suggests that translation of dendritic mRNAs might be regulated by synaptic activity (Steward and Levy, 1982); however, evidence to support this idea has been limited. Afferent stimulation in hippocampal slices has been shown to cause an increased incorporation of labeled amino acids in dendritic laminae when the stimulation was delivered in the presence of a muscarinic cholinergic agonist (Feig and Lipton, 1993). This incorporation suggests local protein synthesis within dendrites. Other evidence has come from studies using subcellular fractions of synaptic terminals with attached dendrites (synaptoneurosomes). Treatment of synaptoneurosomes with metabotrophic glutamate receptor agonists caused a transient increase in the proportion of ribosomes in polyribosomes, suggesting enhanced translation

\footnotetext{
Received March 11, 1999; revised June 25, 1999; accepted July 2, 1999.

This work was supported by National Institutes of Health Grant NS12333 (O.S.), National Science Foundation Grant NSF IBN92-22120 (O.S.), and National Institute of Mental Health Grant NM50861 (S.H.). We thank Christine Duncan and Paula Falk for technical assistance.

Correspondence should be addressed to Dr. Steward at his present address: Reeve-Irvine Research Center, College of Medicine, University of California at Irvine, 1105 Gillespie Neuroscience Research Facility, Irvine, CA 92697. Copyright (C) 1999 Society for Neuroscience $0270-6474 / 99 / 197834-12 \$ 05.00 / 0$
}

(Weiler and Greenough, 1993). Interestingly, an mRNA with sequence homology to fragile $\mathrm{X}$ mental retardation protein was among the mRNAs that were regulated in this fashion (Weiler et al., 1997).

Synaptic activity also triggers a local synthesis of the protein encoded by the immediate early gene Arc (activity-regulated cytoskeletal protein). Stimulation of afferents to particular dendritic segments causes the mRNA for Arc to localize selectively in the activated portion of the dendrite (Steward et al., 1998). Newly synthesized Arc protein accumulates in the same dendritic domains as the newly synthesized mRNA. In this situation, the accumulation of the protein appears to be directly related to the accumulation of the mRNA; it is not clear whether there is also activity-dependent translational regulation of Arc mRNA once it localizes at activated synaptic sites.

To assess whether the translation of dendritic mRNAs can be regulated by synaptic activity, it is useful to focus on mRNAs that are present constitutively in dendrites. Examples include the mRNAs for the dendrite-specific cytoskeletal protein MAP2 and the $\alpha$-subunit of CAMKII (Steward et al., 1996a,b). CAMKII mRNA is of particular interest because of recent evidence that its translation may be regulated via cytoplasmic poly(A) elongation, and the molecular machinery that mediates this process is present in the postsynaptic junction (Wu et al., 1998).

To explore whether synaptic activity regulates dendritic mRNA translation, we activated the pathway from the entorhinal cortex to the dentate gyrus (the perforant path) at frequencies that induce long-term potentiation (LTP) and then used immunocytochemical techniques to assess whether the activation caused an increase in MAP2 and CAMKII protein in the acti- 
vated dendritic domains. We demonstrate that patterned synaptic activation does alter immunostaining patterns for MAP2 and CAMKII, but in different ways. Protein synthesis inhibitors were used to assess whether the changes in immunostaining depended on new protein synthesis.

\section{MATERIALS AND METHODS}

Neurophysiological techniques. Adult male Sprague Dawley rats were anesthetized with urethane and positioned in a stereotaxic apparatus as described previously (Steward et al., 1998). Stimulating and recording electrodes were positioned stereotaxically to activate the pathway from the medial entorhinal cortex (EC) while recording in the dentate gyrus. A monopolar stimulating electrode (an insulated tungsten microelectrode) was positioned at $4.0 \mathrm{~mm}$ lateral to the midline and $1.0 \mathrm{~mm}$ anterior to the transverse sinus. The depth of the stimulating electrode was adjusted to obtain a maximal evoked response in the dentate gyrus at minimal stimulus intensity. Recording electrodes were glass micropipettes filled with $0.9 \%$ saline that were positioned at 3.5 posterior to bregma and $1.5-2.0 \mathrm{~mm}$ lateral to the midline. In some experiments, the micropipettes were filled with various drugs as described below. The recording electrodes were positioned in the cell layer of the dentate gyrus based on the evoked responses generated by EC stimulation.

After the stimulating and recording electrodes were positioned, stimulus intensity was set to evoke a $\sim 1-3 \mathrm{mV}$ population spike. Single test pulses were then delivered at a rate of one every $10 \mathrm{sec}$ for 5-10 min to determine baseline response amplitude. Then trains of high-frequency stimuli (eight pulses at $400 \mathrm{~Hz}$ ) were delivered at a rate of one every 10 $\mathrm{sec}$ for periods ranging from $1.5 \mathrm{~min}$ to $2 \mathrm{hr}$ (see Table 1). At the end of the period of high-frequency stimulation, test responses were delivered to determine the extent of the synaptic potentiation that had been induced. Control experiments involved delivering the same number and intensity of stimuli over the same time period $(2 \mathrm{hr})$ but at a low frequency that does not cause LTP $(0.8$ pulses $/ \mathrm{sec})$.

In two experiments, protein synthesis was blocked globally by injecting cycloheximide (CHX) systemically ( $20 \mathrm{mg} / \mathrm{kg}$ body weight) as described in Wallace et al. (1998). In other experiments, protein synthesis was inhibited locally by positioning recording micropipette electrodes filled with either puromycin or cycloheximide $(20$ or $25 \mathrm{mg} / \mathrm{ml}$ of $0.9 \%$ saline, respectively) in the dentate gyrus. The tips of the electrodes were broken off to promote diffusion of the inhibitors into the tissue. The area of effective protein synthesis inhibition was defined by immunostaining sections for $c$-fos protein, which is strongly induced by the stimulation. The area of effective protein synthesis inhibition produced by diffusion of inhibitors from micropipettes was $\sim 1-2 \mathrm{~mm}$ in diameter.

At the termination of the neurophysiological experiment, rats were given an overdose of anesthetic (Nembutal, $100 \mathrm{mg} / \mathrm{kg}$, i.p.). When deeply anesthetized, the animals were perfused with $4 \%$ paraformaldehyde. The brains were removed and stored in fixative overnight. On the following day, the brains were sectioned on a vibratome, and sections were collected and stored in phosphate buffer, $\mathrm{pH}$ 7.4.

Immunocytochemistry. Free-floating vibratome sections were treated with $\mathrm{H}_{2} \mathrm{O}_{2}$ to block endogenous peroxidase. For some of the antibodies, immunostaining was substantially improved using an antigen retrieval procedure in which sections were heated to $95^{\circ} \mathrm{C}$ for $5 \mathrm{~min}$. Sections were then immunostained using one or more of the following antibodies (see Table 1). (1) Monoclonal antibody AP14, which recognizes MAP2, was used at a dilution of 1:500. This antibody was a gift from A. Frankfurter (University of Virginia, Charlottesville, VA). (2) Monoclonal antibody 6G9, which recognizes the $\alpha$-subunit of CAMKII (Boehringer Mannheim, Indianapolis, IN), was used at a dilution of 1:1000. (3) Monoclonal antibody 22B1 (Affinity Bioreagents), which recognizes CAMKII only when it is phosphorylated on threonine-286, was used at a dilution of 1:250. Sections stained for 22B1 were heat-treated for $5 \mathrm{~min}$. The antibody for c-fos was a rabbit polyclonal antibody. Sections were heattreated, and the antibody was used at a dilution of 1:1000.

Sections were incubated for $72 \mathrm{hr}$ in the primary antibody and then washed and incubated in the secondary antibody for $2 \mathrm{hr}$. For the mouse monoclonal antibodies, the secondary antibody was a horse anti-mouse IgG used at a dilution of 1:100 in 5\% normal horse serum. For the rabbit polyclonal antibody against c-fos, the secondary antibody was goat antirabbit IgG, which was used at a dilution of 1:100 in normal goat serum. Subsequent immunocytochemical procedures were as described in Wallace et al. (1998).
For quantitative assessment of immunostaining, optical density (OD) measurements were taken across the granule cell layer and molecular layer using an M4 Microcomputer Imaging Device (Imaging Research). Digital images were collected at $400 \times$. The light intensity was adjusted so that areas exhibiting background levels of labeling (the white matter) were just above threshold, whereas areas exhibiting maximal levels of labeling (the molecular layer) were within the measuring range. Then, a series of OD measurements were taken across the granule cell layer and molecular layer using a $20 \times 20 \mu \mathrm{m}$ measuring frame. A row of five separate measurements were taken at each level of the granule cell layer and molecular layer, and the OD values at each level (called row numbers in the figures) were averaged. The values in the graphs illustrate the mean and SD of the five measurements.

\section{RESULTS}

The perforant path projections from the EC to the dentate gyrus innervate the outer two-thirds of the molecular layer of the dentate gyrus. Within that zone, the medial EC projects to the middle molecular layer, whereas the lateral EC projects to the outer molecular layer (Steward, 1976). By positioning a stimulating electrode in different parts of the $\mathrm{EC}$, it is possible to selectively activate a band of synapses that terminate in different sublayers of the molecular layer.

In the present experiments, we selectively activated the pathway from the medial entorhinal cortex to the middle dendritic layers of the dentate gyrus (the medial perforant pathway) using a stimulation paradigm that reliably induces LTP $(400 \mathrm{~Hz}$ trains, eight pulses per train, delivered at a rate of one every $10 \mathrm{sec}$ ). Stimulation was delivered for periods ranging from $1.5 \mathrm{~min}$ to $2 \mathrm{hr}$ at an intensity that initially evoked a $1-3 \mathrm{mV}$ population spike. Physiological recordings performed before and after the stimulation period confirmed that the stimulation produced robust synaptic potentiation in every experiment and that the potentiation persisted throughout the recording period (data not shown). The set of animals from which the present observations are derived is indicated in Table 1.

\section{High-frequency stimulation of the perforant path produces a two-stage alteration in immunostaining for MAP2 in the dendritic laminae of the dentate gyrus}

Assessment of MAP2 immunostaining patterns after various periods of stimulation revealed a two-stage alteration in immunostaining. Brief periods of stimulation produced a sharply defined band of decreased immunostaining in the middle molecular layer (the lamina in which the activated synapses terminate). Then, with continued stimulation, two sharply defined bands of increased immunostaining appeared on each side of the activated lamina.

Figure 1 illustrates the decreases in immunostaining seen after brief periods of stimulation (in this case, 30 trains delivered over $5 \mathrm{~min}$ ). The boundary of diminished immunostaining was quite sharp (Fig. 1D, arrows) and appeared to correspond exactly to the location of the band of synapses that would have been activated. The band of decreased immunostaining could be seen after as few as eight trains delivered over a period of $1.5 \mathrm{~min}$ (data not shown), but these early decreases were not as dramatic as those seen after 30 trains.

Longer periods of stimulation produced a striking trilaminar staining pattern, in which there were bands of increased immunostaining on each side of the activated lamina. Figure 2 illustrates an example of the staining pattern after $2 \mathrm{hr}$ of stimulation. Typically, the band of increased immunostaining located proximal to the cell body layer appeared darker than the band of increased immunostaining distal to the activated lamina.

The time course of development of the trilaminar staining 


\begin{tabular}{|c|c|c|c|}
\hline Case no. & $\begin{array}{l}\text { Stimulation } \\
\text { time }\end{array}$ & Antibodies tested & $\begin{array}{l}\text { Other } \\
\text { treatment }\end{array}$ \\
\hline 02109a & $5 \min$ & CAMKII, MAP2 & \\
\hline $02109 b$ & $5 \mathrm{~min}$ & CAMKII, MAP2 & \\
\hline 12145 & $5 \mathrm{~min}$ & MAP2 & \\
\hline 02146 & $5 \min$ & MAP2 & \\
\hline 03196 & $1.5 \mathrm{~min}$ & MAP2 & \\
\hline $08056 \mathrm{a}$ & $5 \mathrm{~min}$ & MAP2 & \\
\hline $08056 b$ & $5 \min$ & MAP2 & \\
\hline 09106a & $5 \min$ & MAP2 & \\
\hline $02047 \mathrm{a}$ & $5 \min$ & MAP2 & \\
\hline 02267 & $30 \mathrm{~min}$ & MAP2, CAMKII & \\
\hline 03047 & $30 \mathrm{~min}$ & MAP2, CAMKII & \\
\hline 03247 & $45 \mathrm{~min}$ & MAP2, CAMKII & \\
\hline 05227 & $1 \mathrm{hr}$ & MAP2 & \\
\hline 06267 & $2 \mathrm{hr}$ & MAP2, CAMKII, c-fos & \\
\hline 06277 & $2 \mathrm{hr}$ & MAP2, CAMKII & \\
\hline 07027 & $2 \mathrm{hr}$ & MAP2, CAMKII, Arc* & CHX systemic \\
\hline 09297 & $2 \mathrm{hr}$ & MAP2, CAMKII, c-fos & CHX systemic \\
\hline 09307a & $2 \mathrm{hr}$ & MAP2, CAMKII, c-fos & CHX local \\
\hline 09307b & $2 \mathrm{hr}$ & MAP2, CAMKII, c-fos & CHX local \\
\hline 01218a & $2 \mathrm{hr}$ & MAP2, CAMKII, c-fos & PUR local \\
\hline 01228 & $3 \min$ & MAP2, CAMKII & \\
\hline 01248a & $2 \mathrm{hr}$ & MAP2, CAMKII, c-fos & PUR local \\
\hline 07088 & $30 \mathrm{~min}$ & MAP2, CAMKII & \\
\hline 07098 & $1 \mathrm{hr}$ & MAP2, CAMKII & \\
\hline 07108 & $2 \mathrm{hr}$ & MAP2, CAMKII, P-CAMKII & AP5 local \\
\hline $09148 \mathrm{c}$ & $2 \mathrm{hr}$ & MAP2, CAMKII & AP5 local \\
\hline $09168 \mathrm{a}$ & $2 \mathrm{hr}$ & MAP2, CAMKII & AP5 local \\
\hline 09218 & $2 \mathrm{hr}$ & MAP2, CAMKII & MK801 local \\
\hline 11028 & $2 \mathrm{hr}$ & MAP2, CAMKII & MK801 local \\
\hline $11038 \mathrm{c}$ & $2 \mathrm{hr}$ & MAP2, CAMKII & MK801 local \\
\hline 11228 & $2 \mathrm{hr}$ & MAP2, CAMKII & MK801 local \\
\hline 01039 & $2 \mathrm{hr}$ & MAP2, CAMKII, c-fos & CHX local \\
\hline 01159 & $2 \mathrm{hr}$ & MAP2, CAMKII, c-fos & MK801 local \\
\hline 01189 & $2 \mathrm{hr}$ & MAP2, CAMKII, c-fos, P-CAMKII & \\
\hline 01199 & $2 \mathrm{hr}$ & MAP2, CAMKII, c-fos & \\
\hline $02039 \mathrm{~g}$ & $2 \mathrm{hr}$ & MAP2, CAMKII, c-fos, P-CAMKII & MK801 local \\
\hline 04259 & $2 \mathrm{hr}$ & MAP2, CAMKII, c-fos & PUR local \\
\hline $05239 \mathrm{a}$ & $2 \mathrm{hr}$ & MAP2, CAMKII, c-fos & CHX local \\
\hline 05239b & $2 \mathrm{hr}$ & MAP2, CAMKII, c-fos & \\
\hline
\end{tabular}

pattern is illustrated in Figure 4. After $30 \mathrm{~min}$ of stimulation, there was no detectable increase in immunostaining in the sideband laminae, although a band of decreased immunostaining could still be seen in the middle molecular layer. The bands of increased immunostaining were detectable at $1 \mathrm{hr}$, especially the more proximal band, and by $2 \mathrm{hr}$, the full trilaminar staining pattern was evident.

\section{Synaptic activation produces a selective increase in immunostaining for CAMKII in the activated lamina}

High-frequency stimulation of the medial perforant path also caused an alteration in the immunostaining pattern for CAMKII; however, the nature of the change was different than for MAP2. In particular, synaptic activation led to the development of a sharply defined band of increased immunostaining in the middle molecular layer that had been synaptically activated (Figs. $3 B, D$, 4). This band seemed to exist in exactly the same lamina in which
MAP2 immunostaining was decreased. The band of increased immunostaining for CAMKII was detectable after brief periods of stimulation ( $5 \mathrm{~min}$ ) (data not shown) but appeared more distinct with longer periods of stimulation (Fig. 4). Also, after 2 hr of stimulation, there was a hint of a more complicated lamination pattern in which the band of increased immunostaining was bounded on each side by bands of slightly decreased immunostaining, resulting in a trilaminar pattern that was essentially a mirror image of the pattern seen with MAP2 (Fig. 3D).

To obtain a quantitative measure of the alterations in immunostaining, OD measurements were taken across the molecular layer in six representative cases that had been stimulated for $2 \mathrm{hr}$. Figure 5 illustrates an example of the results from one animal. To obtain a single quantitative measure of the alteration in MAP2 immunostaining, we calculated the mean difference in OD between the activated lamina and the outermost band of increased labeling (Fig. 5C). To quantify the alteration in CAMKII immunostaining, we calculated the mean difference in OD between the peak of staining in the activated lamina and the immediately adjacent inner molecular layer (Fig. $5 F$ ). These quantitative assessments revealed that in the six cases that were evaluated, the average difference in OD between central (activated) and sideband laminae was $18 \pm 6 \%$ for MAP2 (that is, the OD in the outermost band of increased staining was $19 \%$ higher than the OD in the activated lamina). In the case of CAMKII, the OD was $32 \pm 5 \%$ higher in the activated lamina than in the inner molecular layer.

\section{Stimulation-induced alterations in immunostaining for MAP2 and CAM kinase II are mediated by NMDA receptor activation}

The stimulation paradigm that was used strongly activates NMDA receptors, and NMDA receptor activation is thought to be critical for inducing long-term changes in synaptic efficacy. Hence, we assessed whether the stimulation-induced changes in immunostaining were mediated by NMDA receptor activation. To address this question, micropipette recording electrodes were filled with NMDA antagonists (AP5 or MK801). As documented below, diffusion of the antagonist from the recording electrode blocked NMDA receptor activation in a defined region surrounding the micropipette.

To document the efficacy of antagonist action, we recorded synaptic responses via the antagonist-filled micropipette and evaluated whether the NMDA antagonists blocked the induction of LTP. For this experiment, we first positioned a micropipette filled with saline in the molecular layer to record the negative-going population EPSP. Control responses were collected, and then the saline-filled electrode was replaced with one filled with MK801 (10 $\mathrm{mg} / \mathrm{ml})$. The saline-filled control micropipette was then repositioned at a distant site in the dentate gyrus. The population EPSPs elicited by single-pulse stimulation were of comparable amplitude before and after the placement of the MK801-filled micropipette (data not shown). Nevertheless, the potentiation of the population EPSP was completely blocked at the site of the MK801-filled micropipette but not at the distant control site (Fig. 6).

To actually visualize the area in which NMDA receptors had been effectively blocked, we evaluated the stimulation-induced expression of the immediate early gene c-fos. High-frequency stimulation of the perforant path strongly induced c-fos protein expression in dentate granule cells (Fig. 7A); however, c-fos induction was completely blocked in an area $\sim 1 \mathrm{~mm}$ in diameter 

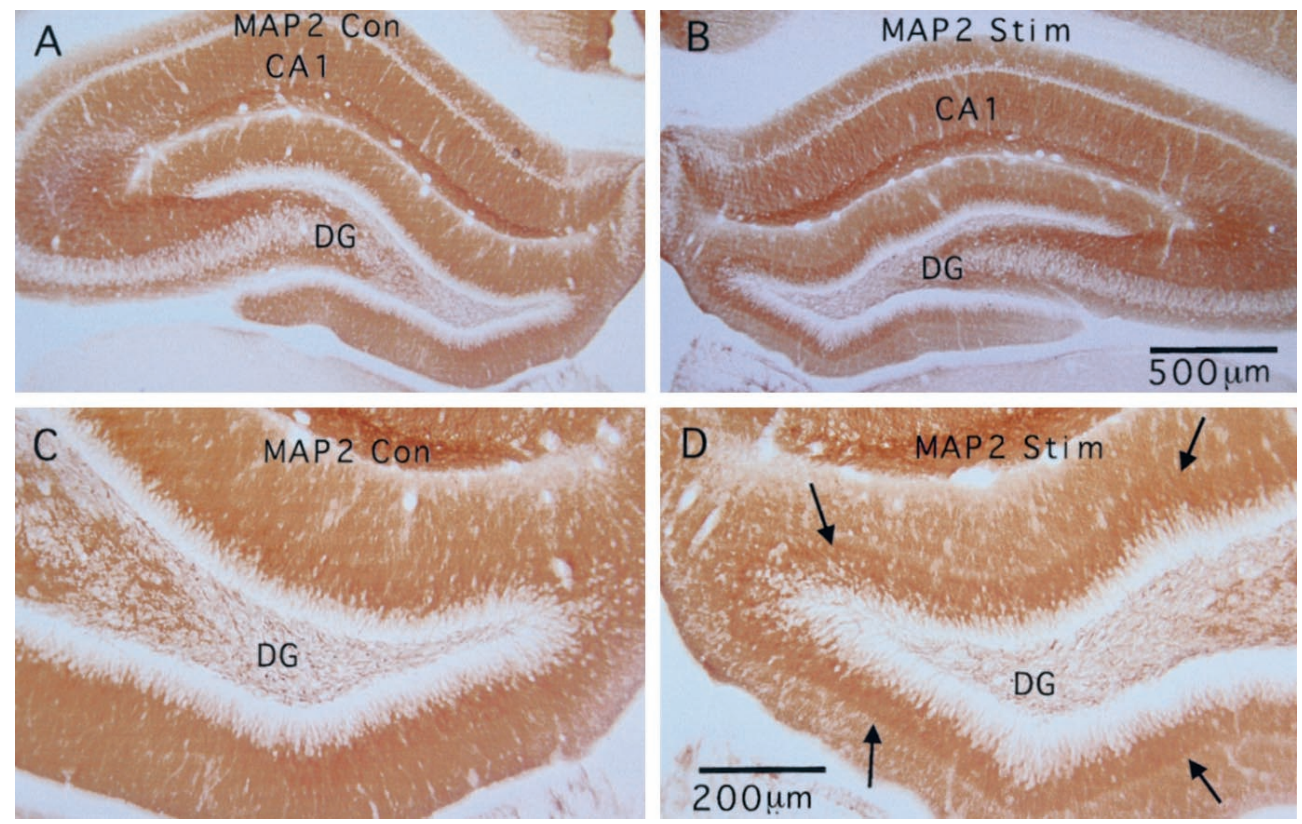

Figure 1. Immunostaining pattern for MAP2 in the dentate gyrus after $5 \mathrm{~min}$ of high-frequency stimulation of the medial perforant path. $A$, Control immunostaining pattern contralateral to the stimulation (MAP2 Con); $B$, immunostaining pattern on the side in which the perforant path had received 5 min of highfrequency stimulation (MAP2 Stim); $C$, $D$, higher magnification views. Note the discrete band of decreased immunostaining in the middle molecular layer (arrows) corresponding exactly to the band of synapses that would have been activated. $C A 1$, CA1 region of the hippocampus; $D G$, dentate gyrus. that surrounded the MK801-filled micropipette (Fig. 7A, arrows). The local blockade of c-fos induction provides a striking visual marker for the area in which NMDA receptors have been blocked, and the strong induction in distant sites provides a useful intra-animal control. Figure $7 C-F$ illustrates the pattern of immunostaining for MAP2 and CAMKII in sections from the animal illustrated in Figure $7 A$. Stimulation-induced alterations in immunostaining for both MAP2 and CAMKII were eliminated in approximately the same area in which c-fos induction was blocked, whereas alterations in immunostaining persisted at locations distant from the antagonist-filled micropipette.

To document these results quantitatively, OD measurements were taken across the molecular layer in the areas indicated in Figure 7 (lower case letters $a-i$ ). The results of these scans are illustrated in the graphs of Figure $8 A-I$. The strong induction of c-fos that normally occurs as a consequence of the stimulation (Fig. $8 A$ ) is completely blocked in the area near the MK801-filled micropipette (Fig. 8B). The trilaminar staining pattern for MAP2 is present in areas distant from the MK801 site (Fig. 8D) but is not seen in the area near the MK801-filled micropipette (Fig. $8 E$ ). Similarly, the increase in immunostaining for CAMKII is clearly seen in areas distant from the MK801 site (Fig. 8G) but not in the area near the MK801-filled micropipette (Fig. $8 H$ ).

Essentially identical results were obtained in one additional experiment involving MK801 and in two other experiments in which the recording micropipette was filled with AP5 $(10 \mathrm{mg} / \mathrm{kg})$. Taken together, these results provide strong evidence that the alterations in immunostaining for both MAP2 and CAMKII are mediated by NMDA receptor activation.

\section{Stimulation-induced alterations in immunostaining for MAP2 are diminished by inhibiting protein synthesis, whereas the increases in immunostaining for CAMKII are not}

To determine whether the lamina-specific increases in immunostaining for MAP2 and CAMKII required protein synthesis, we
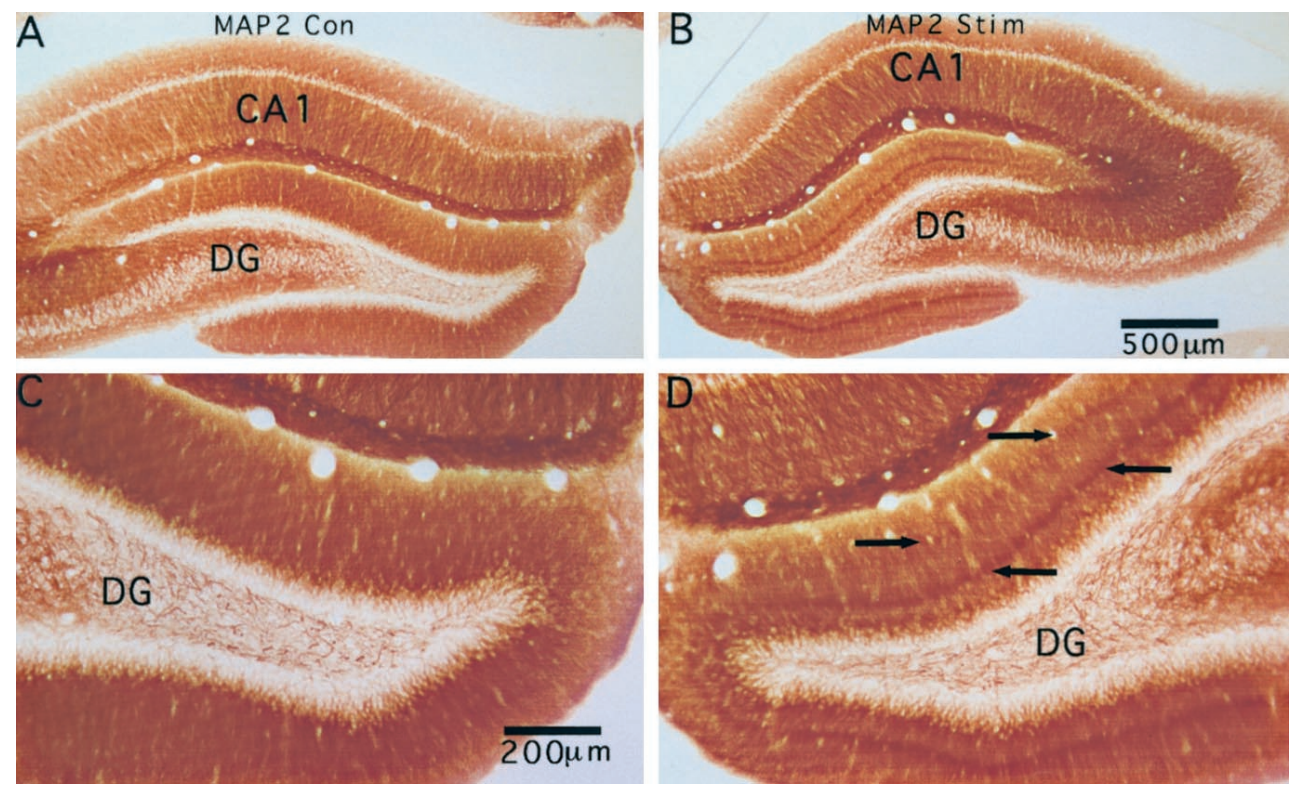

Figure 2. Immunostaining pattern for MAP2 in the dentate gyrus after $2 \mathrm{hr}$ of high-frequency stimulation of the medial perforant path. $A$, Control immunostaining pattern contralateral to the stimulation (MAP2 Con); B, immunostaining pattern on the side in which the perforant path had received $2 \mathrm{hr}$ of high-frequency stimulation (MAP2 Stim); $C, D$, higher magnification views. Note the trilaminar staining pattern in the molecular layer in which the central (activated) band was bounded by two thin bands of increased immunostaining (arrows). CA1, CA1 region of the hippocampus; $D G$, dentate gyrus. 

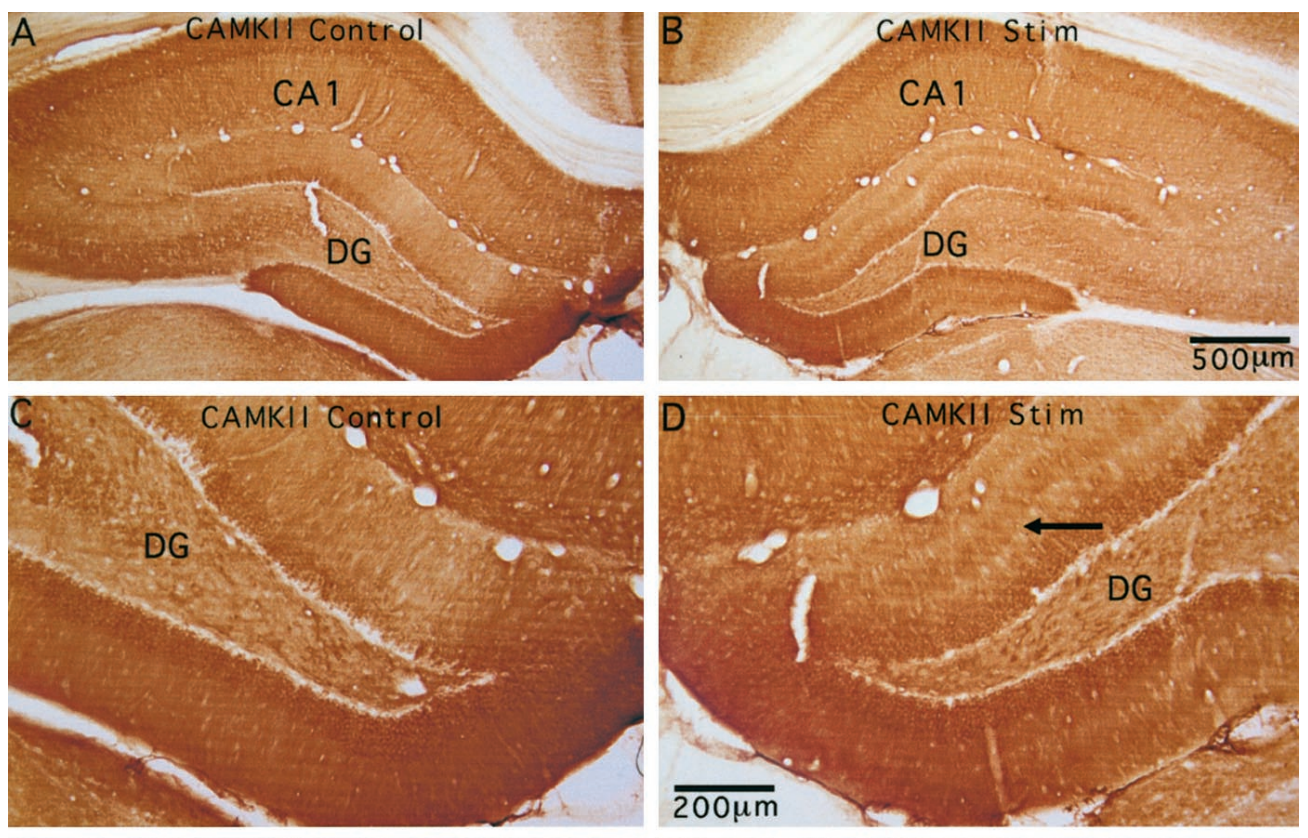

Figure 3. Immunostaining pattern for CAMKII in the dentate gyrus after $2 \mathrm{hr}$ of high-frequency stimulation of the medial perforant path. $A$, Control immunostaining pattern contralateral to the stimulation (CAMKII Control); B, immunostaining pattern on the side in which the perforant path had received $2 \mathrm{hr}$ of high-frequency stimulation (CAMKII Stim); $C, D$, higher magnification views. Note the discrete band of increased immunostaining in the middle molecular layer (arrows) corresponding exactly to the band of synapses that would have been activated. $C A 1$, CA1 region of the hippocampus; $D G$, dentate gyrus. $E$ and $F$ compare immunostaining patterns for pan- $\alpha$ CAMKII (monoclonal antibody 6G9) and phosphoepitopespecific CAMKII (monoclonal antibody 22B1). These sections are from a different case than the one illustrated in $A-D$.
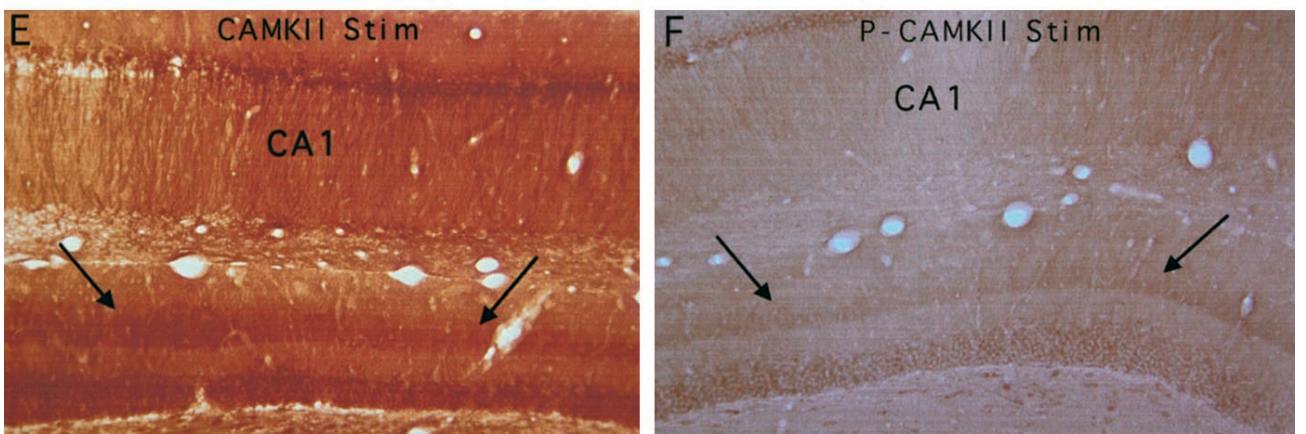

evaluated whether the alterations in immunostaining were blocked by inhibiting protein synthesis during the stimulation period. Two approaches were used. In the first, protein synthesis was blocked by a single systemic injection of cycloheximide (20 $\mathrm{mg} / \mathrm{kg}$, i.p.). Such systemic injections inhibit protein synthesis in brain by $\sim 90 \%$, although protein synthesis recovers to $\sim 50 \%$ of control levels over the course of $\sim 4 \mathrm{hr}$. In the second approach, protein synthesis was inhibited locally by positioning micropipettes filled with puromycin $(25 \mathrm{mg} / \mathrm{ml}$ in saline) or cycloheximide $(20 \mathrm{mg} / \mathrm{ml}$ in saline) in the dentate gyrus.

To document the effectiveness of the protein synthesis inhibitors, we again evaluated the stimulation-induced expression of the immediate early gene $c$-fos. In animals not treated with protein synthesis inhibitors, high-frequency stimulation of the perforant path strongly induced c-fos protein expression in dentate granule cells (Fig. 9A). As expected, a systemic injection of cycloheximide greatly attenuated this induction of c-fos protein (Fig. $8 C$ ). In this same animal, the alterations in MAP2 immunostaining on the stimulated side were considerably less prominent than in control animals (Fig. $8 E$ ), although the trilaminar staining pattern could still be detected in part of the dentate gyrus. Inhibition of protein synthesis did not block the development of the discrete band of increased immunostaining for CAMKII. The band of increased immunostaining in the animal that received $\mathrm{CHX}$ appeared comparable to that seen in animals that had not received CHX (Fig. 9G).
In cases in which protein synthesis inhibitors were delivered via diffusion from a micropipette, c-fos induction was blocked in an area $\sim 1-2 \mathrm{~mm}$ in diameter surrounding the micropipette. For example, Figure 10 illustrates a case in which cycloheximide was present in the micropipette. In this case, the alterations in immunostaining for MAP2 were less prominent in the area around the cycloheximide-filled micropipette (Fig. 10C), although again, some evidence of a trilaminar staining pattern could still be seen. At the same time, the alterations in MAP2 immunostaining were clearly evident in sections taken from parts of the hippocampus that were distant from the micropipette. Similar results were obtained when the micropipette contained puromycin (data not shown). Again, however, local inhibition of protein synthesis did not block the development of the discrete band of increased immunostaining for CAMKII.

To document these results quantitatively, we used the same strategy that we used to document the effects of local injections of MK801. In three representative cases that had been treated with CHX, OD measurements were taken across the molecular layer in the areas near the inhibitor-filled pipette and in distant areas. A single quantitative measure of the alteration in immunostaining was then determined as in Figure 5C,F, enabling us to calculate the average change in immunostaining at the site of $\mathrm{CHX}$ application in comparison to distant sites (Fig. 11). The results of this analysis confirmed the qualitative assessments. The strong induction of c-fos that normally occurs as a consequence of the stim- 

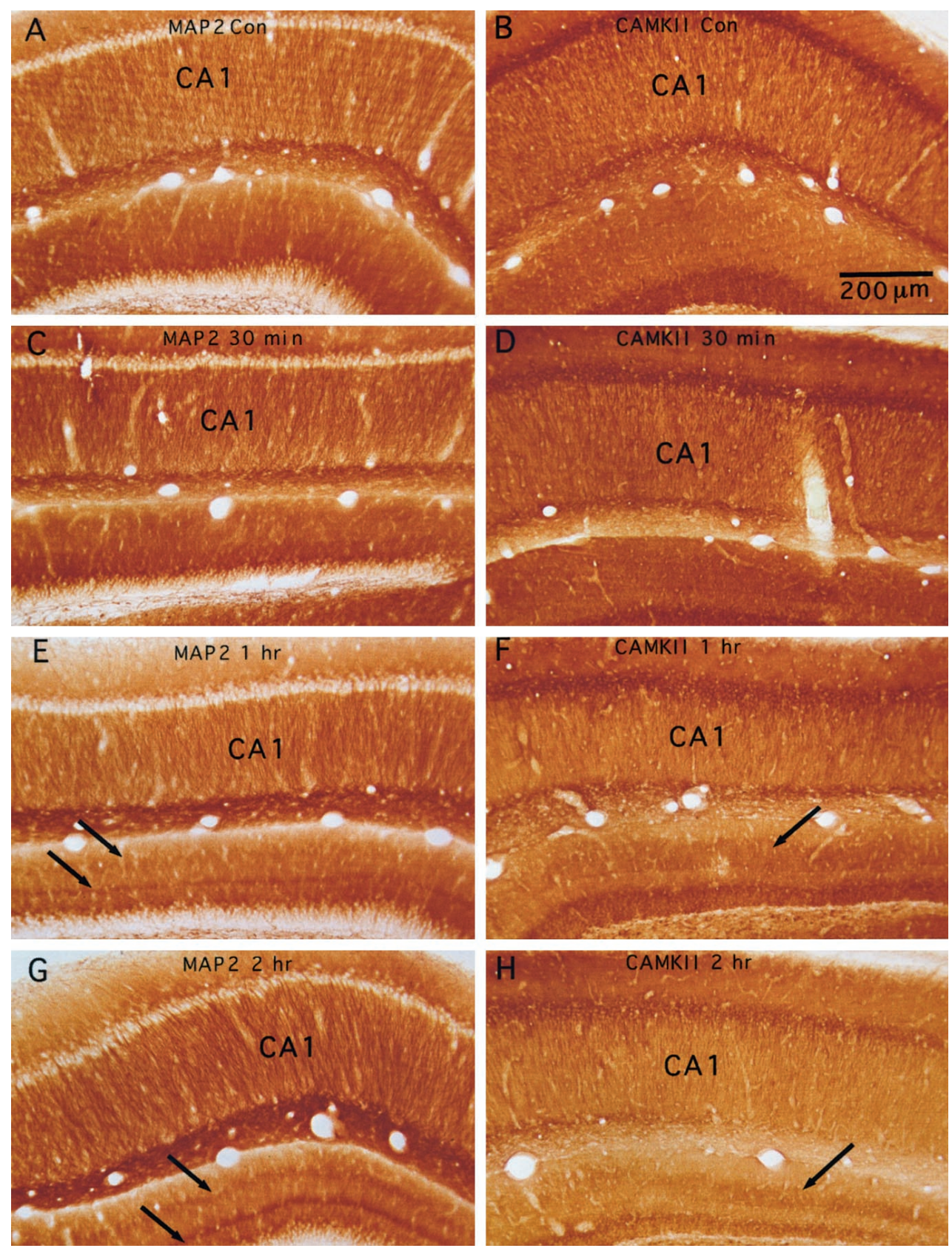

Figure 4. Time course of alterations in immunostaining for MAP2 and CAMKII after high-frequency stimulation of the medial perforant path. $A$ and $B$ illustrate the control pattern of immunostaining for MAP2 $(A$; $M A P 2$ Con) and CAMKII (B; CAMKII $C o n)$ in the dorsal blade of the dentate gyrus; $C, E$, and $G$ illustrate the pattern of immunostaining for MAP2 after $30 \mathrm{~min}, 1$ $\mathrm{hr}$, and $2 \mathrm{hr}$ of high-frequency stimulation. $D, F$, and $H$ illustrate the pattern of immunostaining for CAMKII after $30 \mathrm{~min}, 1 \mathrm{hr}$, and $2 \mathrm{hr}$ of stimulation. Arrows indicate bands of increased immunostaining. ulation is completely blocked in the area near the CHX-filled micropipette (Fig. 11 $A$ ), the alteration in immunostaining for MAP2 is diminished, but not eliminated, in the area near the CHX-filled micropipette (Fig. 11B), and the increase in immunostaining for CAMKII is only slightly diminished in the area near the CHX-filled micropipette (Fig. 11C).

Similar results were obtained in the three experiments in which puromycin was present in the recording electrode, except that in two cases, the area of protein synthesis inhibition was larger, extending for several millimeters. Throughout the area of inhibition, the induction of c-fos was eliminated, and the alterations in immunostaining for MAP2 were substantially diminished. The larger size of the area of inhibition in two cases made it difficult to compare alterations near the puromycin site and at distant locations. Thus, we did not perform quantitative assessments on these two cases.

\section{Controls}

The antibodies for MAP2 and CAMKII have been extensively characterized in terms of their specificity. In the protocols used here, omission of either the primary or the secondary antibody eliminated immunostaining completely. An additional internal control that these experiments provide is the laminar specificity of the alterations in immunostaining for MAP2 and CAMKII. Immunostaining for MAP2 increased in the laminae on each side of the activated zone, whereas immunostaining for CAMKII increased in the activated zone. This complementary pattern virtually guarantees that the results are not caused by some nonspecific alterations in tissue permeability for antibodies or reagents, dendritic swelling, or a general change in the dendritic cytoskeleton.

One possibility is that the changes in immunostaining reflect 


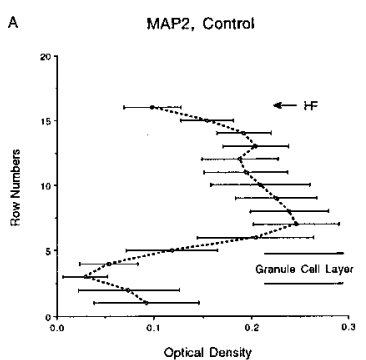

Figure 5. Quantitative assessment of immunostaining for MAP2 and CAMKII after $2 \mathrm{hr}$ of high-frequency stimulation. The graphs illustrate the average optical density $(O D)$ of labeling across the molecular layer on the control side contralateral to the stimulation $(A$, MAP2, Control; D, CAMKII, Control) and on the side of the stimulation $(B$, MAP2, EC Stim; E, CAMKII, EC Stim). Bars indicate plus or minus $1 \mathrm{SD}$ of the five measurements at each level of the molecular layer. $C$ and $F$ are expanded versions of the graphs in $B$ and $D$, which illustrate the method of quantification for MAP2 and CAMKII, respectively. For further details, see Results. HF, Hippocampal fissure.

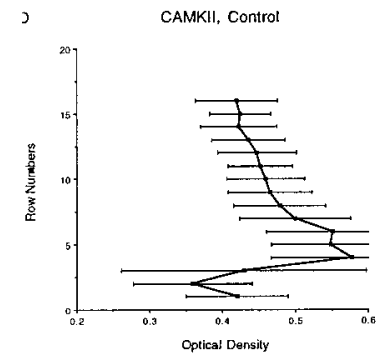

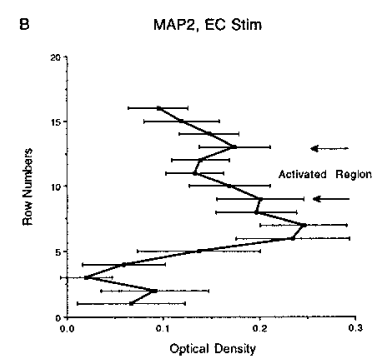
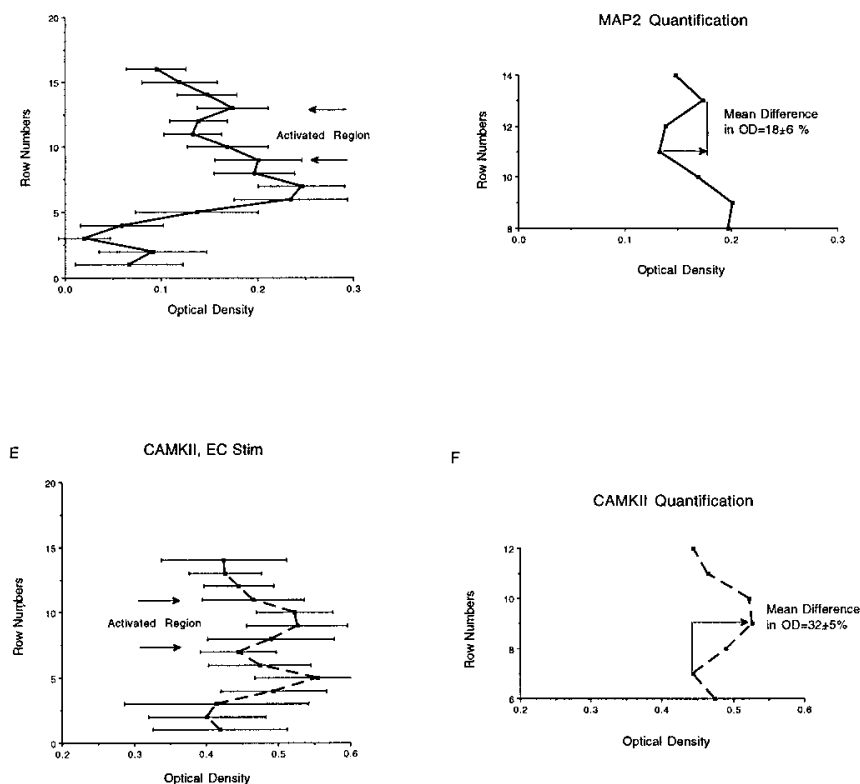

LOCAL BLOCKADE WITH MK801

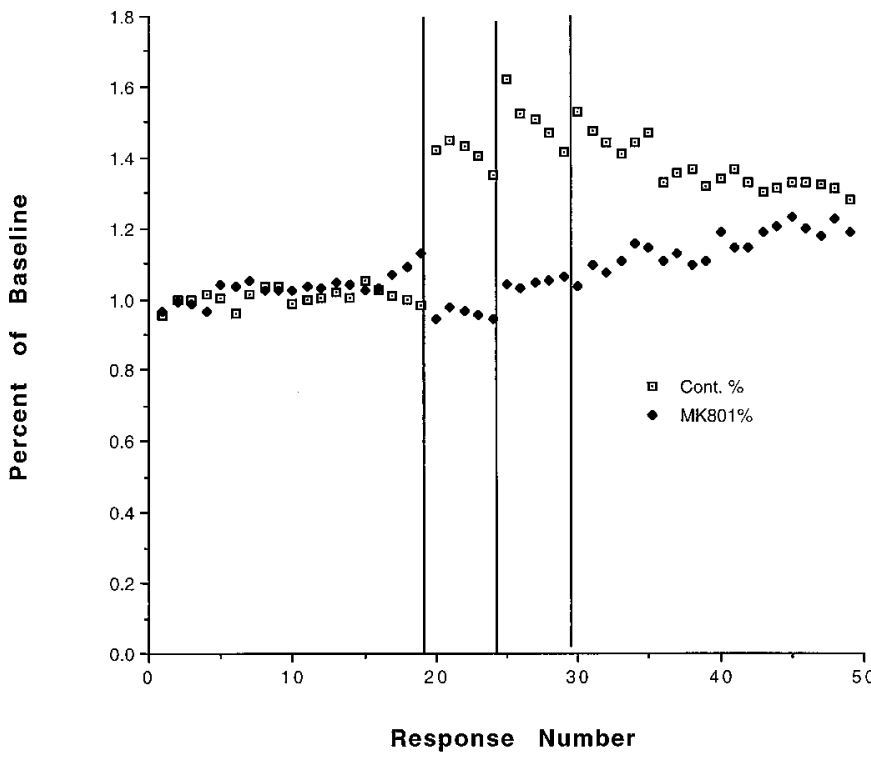

Figure 6. Local blockade of NMDA receptors blocks the induction of LTP after high-frequency stimulation of the perforant path. The graph plots the slope of population EPSPs recorded via an MK801-filled electrode and a distant saline-filled control electrode. Single test pulses were delivered at a rate of one every $10 \mathrm{sec}$ to determine baseline response amplitude, then a series of three series of trains of $400 \mathrm{~Hz}$ stimuli $(10$ pulses per train, 10 trains) were delivered, collecting 10 test responses between each train. Note the increase in response amplitude at the control site and the absence of any change in response amplitude at the MK801 site. After this testing paradigm was completed, trains of stimuli were delivered for an additional $2 \mathrm{hr}$, after which the rat was perfused for immunocytochemistry. The pattern of immunostaining in this case is illustrated in Figure 7.

local changes in the conformation and/or phosphorylation state of the respective molecules. The fact that the changes in MAP2 immunostaining are sensitive to protein synthesis inhibition argues against this idea for MAP2, although it cannot be excluded that part of the observed changes are caused initially by changes in the phosphorylation state of MAP2. Nevertheless, we tested a phosphoepitope-specific antibody against MAP2 termed AP18 (Berling et al., 1994). The same pattern of change in immunostaining was seen with AP18 as described above for AP14 (data not shown).

In the case of CAMKII, we tested antibodies that recognize CAMKII only when it is phosphorylated on threonine-286 (PCAMKII). If the alterations in immunostaining that are seen with the pan- $\alpha$ CAMKII antibody are caused by conformational changes associated with phosphorylation at Thr-286, then the alterations might be revealed more dramatically using the phosphoepitope-specific antibody. As illustrated in Figure $3 E, F$, the pattern of increased immunostaining appeared to be generally comparable whether sections were stained with the P-CAMKII antibody or the pan- $\alpha$ CAMKII antibody.

One interesting aside regarding the immunostaining pattern for c-fos is that there was a very light band of staining in the activated lamina (Figs. 7, 9). This band was not seen in the control experiments in which the primary antibody was omitted. This band was not seen in areas in which c-fos induction was blocked by M K801 (Fig. 7A). Interestingly, however, the band could still be seen when c-fos protein synthesis was blocked by cycloheximide (Figs. $9,10)$. This persistence is not likely to be caused by an incomplete blockade of protein synthesis because immunostaining over the cell body lamina was completely blocked by local cycloheximide, whereas the light band of staining in the dendritic lamina was still present in the area of local blockade (Fig. 10A). Hence, this lightly stained band may not reflect the presence of bona fide c-fos protein and may instead reflect the accumulation of a fos-related antigen in the activated lamina or nonspecific staining unique to the c-fos antibody that is somehow disrupted by MK801.

\section{DISCUSSION}

The purpose of this study was to evaluate whether the translation of two representative dendritic mRNAs could be regulated by intense synaptic activity. We reasoned that patterns of activity that induced protein synthesis-dependent forms of synaptic plasticity might be especially likely to regulate translation of mRNAs 

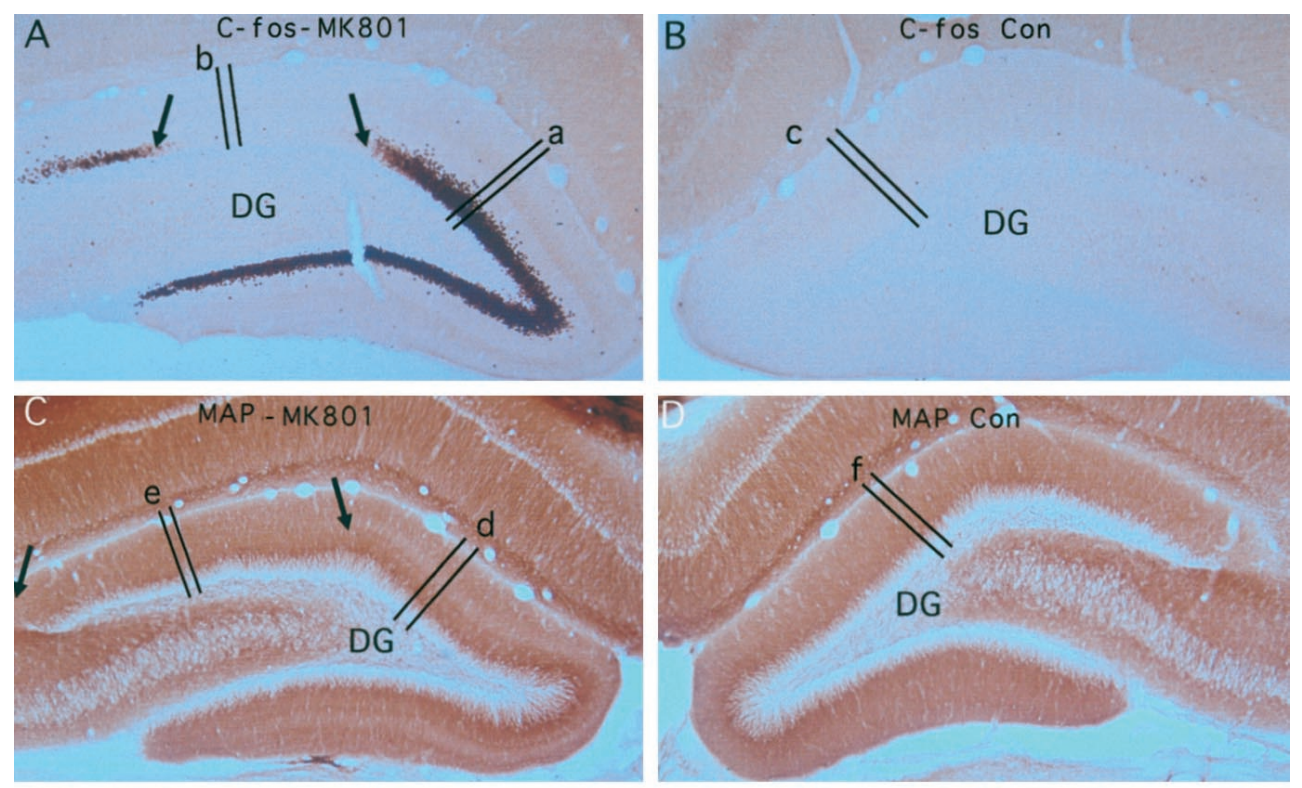

Figure 7. Stimulation-induced alterations in immunostaining for MAP2 and CAMKII are blocked by NMDA receptor antagonists. $A$, Immunostaining for c-fos protein after $2 \mathrm{hr}$ of high-frequency stimulation of the perforant path. A micropipette filled with MK801 was positioned in the dorsal blade of the dentate gyrus near the level of this section. Note the virtually complete blockade of c-fos induction in part of the dorsal blade between the arrows. $B$ illustrates the pattern
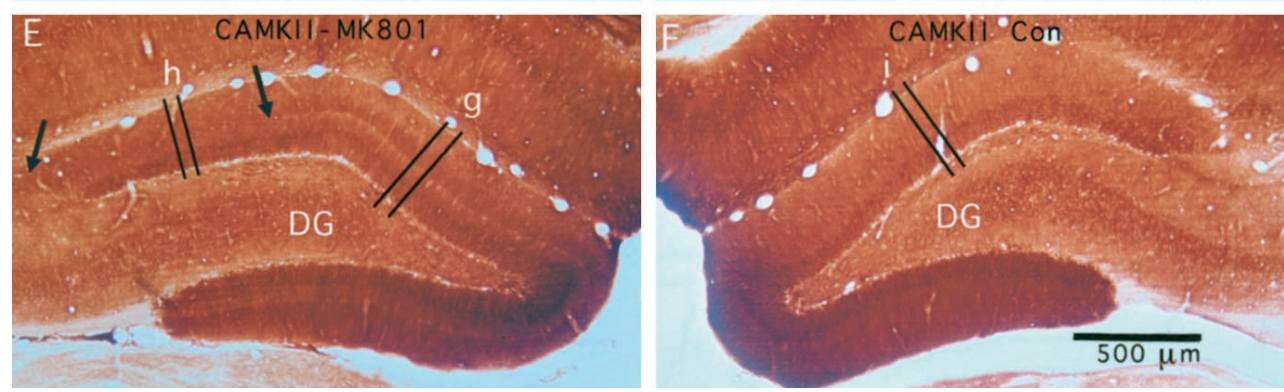
of immunostaining for $\mathrm{c}$-fos on the control side contralateral to the stimulation. $C$ and $D$ illustrate nearby sections stained for MAP2; $E$ and $F$ illustrate sections stained for CAMKII. Note the absence of alterations of immunostaining in the dorsal blade in approximately the same area in which c-fos induction is blocked. Abbreviations are as for Figure 1. The lower case letters $(a-i)$ indicate the areas in which OD measurements were taken for the graphs of Figure $8 A-I$, respectively.

that are present in dendrites constitutively. The enduring form of LTP induced by perforant path stimulation meets this criterion (Krug et al., 1984; Frey et al., 1988). We were especially interested in the possibility that synaptic stimulation might induce CAMKII synthesis, because of recent evidence demonstrating a mechanism for regulating CAMKII translation via cytoplasmic poly(A) elongation (Wu et al., 1998).

Our results revealed that stimulation patterns that induce LTP in the perforant path do alter immunostaining patterns for both MAP2 and CAMKII in dendritic laminae in the dentate gyrus in highly specific ways. The nature of the alterations was different for the two molecules, however, and only the alterations in MAP2 immunostaining were detectably affected by inhibiting protein synthesis. We will consider the findings for MAP2 and CAMKII separately.

\section{Synaptic activation causes a local decrease in MAP2 levels in the activated dendritic domains and increases in adjacent domains}

The alterations in immunostaining for MAP2 appeared to occur in two phases. Initially, synaptic activation led to decreases in immunostaining in the activated lamina. Then, over time, discrete bands of increased immunostaining appeared on each side of the activated lamina.

The most obvious interpretation of the rapid decrease in immunostaining is that intense synaptic activity causes a local degradation of MAP2 in the activated dendritic domain. The strong activation of NMDA receptors certainly leads to $\mathrm{Ca}^{2+}$ influx into dendrites; this influx could activate calcium-activated proteases (calpains) that are capable of cleaving MAP2 (Siman and
Noszek, 1988) as well as other molecules (Seubert et al., 1988). Excitotoxic neuronal injury, traumatic brain injury, and focal ischemia also cause a rapid decrease in MAP2 immunostaining, consistent with calpain-mediated degradation (Siman and Noszek, 1988; Taft et al., 1992; Felipo et al., 1993; Pettigrew et al., 1996). The novel finding of the present study is that intense, brief, physiological, synaptic barrage also leads to decreases in MAP2 immunostaining consistent with degradation, and that these changes occur in very discrete dendritic domains that have been synaptically activated.

With more prolonged stimulation, two defined bands of increased immunostaining appeared just adjacent to the band of activated synapses. This trilaminar staining pattern, with decreases in immunostaining in the activated lamina and increases in the immediately adjacent sidebands, implies that synaptic activation produces a different set of signals in the activated and immediately adjacent dendritic domains. Whatever the mechanism of these changes may be, the data reveal a striking domainspecific alteration in a key molecule of the dendritic cytoskeleton as a consequence of lamina-specific synaptic activation.

The rationale of the present study suggests one possible interpretation of the slowly developing increases in MAP2 immunostaining in the sideband laminae: that the stimulation upregulated MAP2 protein synthesis in the dendritic domains adjacent to the activated zone. The fact that the alterations in immunostaining were partially blocked by protein synthesis inhibitors is consistent with this interpretation. Nevertheless, a hint of a trilaminar staining pattern was still detectable following either systemic or local blockade of protein synthesis. It is not likely that the partial preservation of the induced trilaminar pattern reflects an incom- 

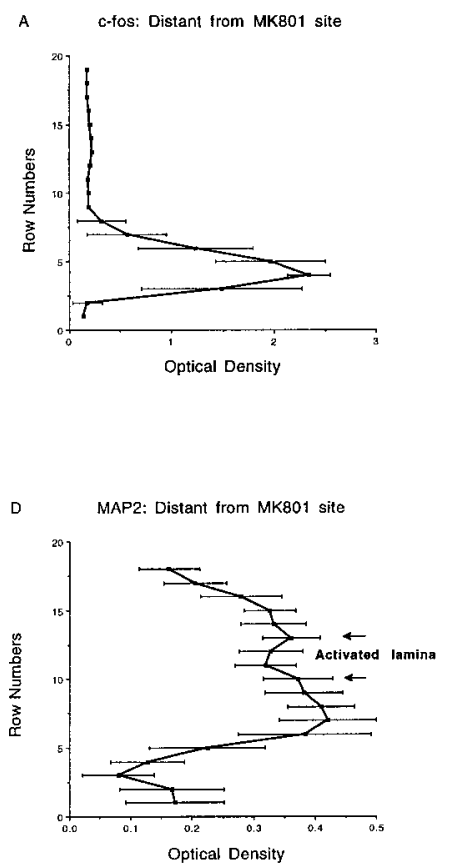

Figure 8. Quantitative analysis of stimulation-induced alterations in immunostaining for c-fos, MAP2, and CAMKII in the presence of NMDA receptor antagonists. The graphs illustrate the average OD of labeling across the molecular layer in the areas indicated by lower case letters $a-i$ in Figure 7 . Error bars indicate \pm 1 SD of the five measurements at each level of the molecular layer. Note that at the MK801 site, there is complete blockade of c-fos induction $(B)$, an elimination of the trilaminar staining pattern for MAP2 $(E)$, and an elimination of the discrete band of increased immunostaining for CAMKII.

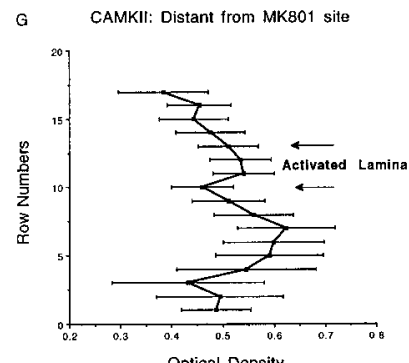

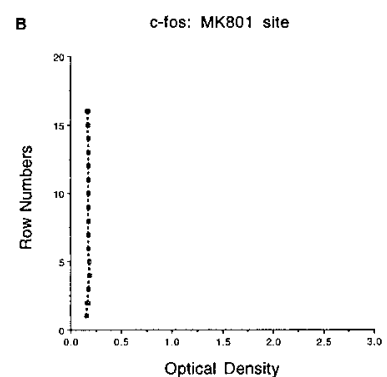
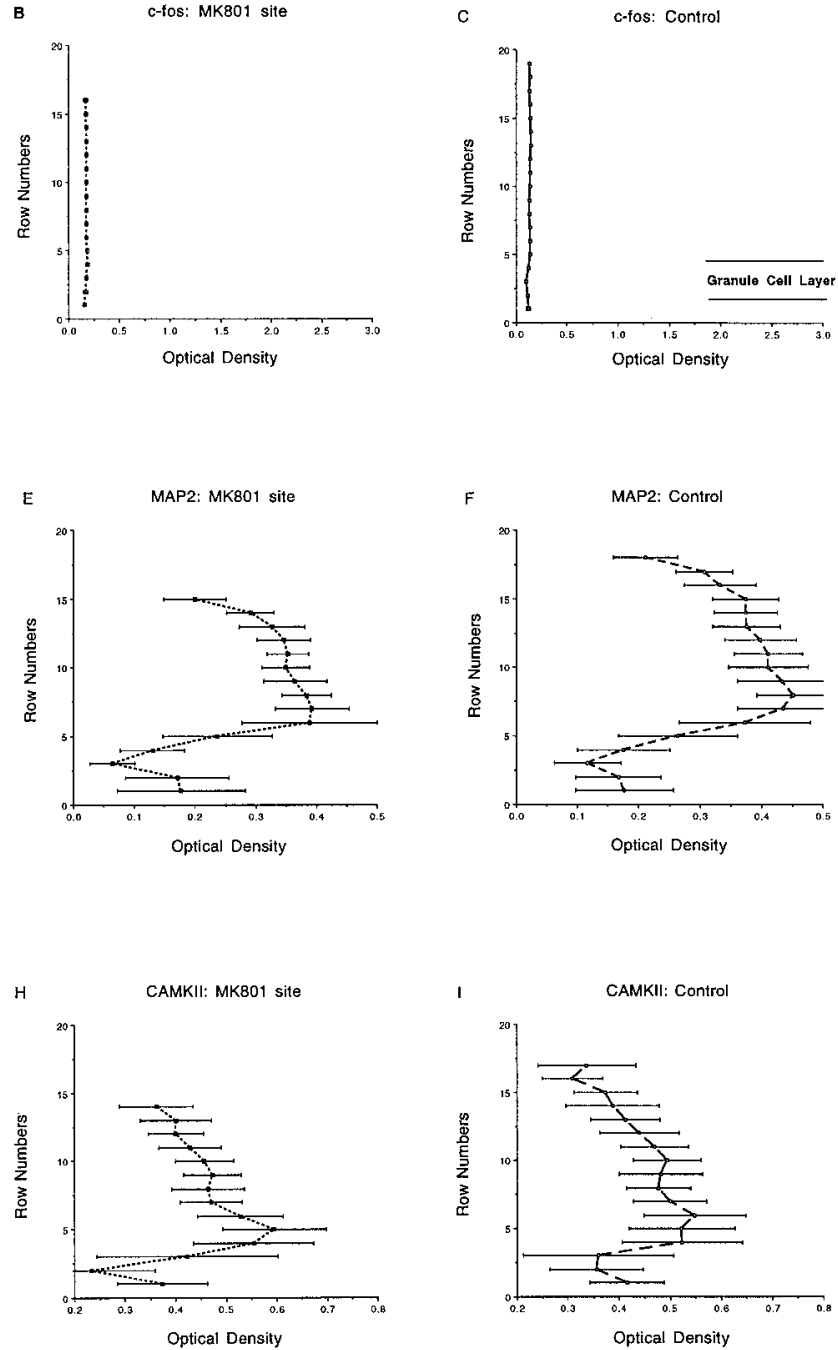

plete inhibition of protein synthesis, because the inhibition of induced c-fos protein synthesis appeared to be complete. Hence, at least part of the change in MAP2 immunostaining may be attributable to something other than new protein synthesis.

One possibility is that part of the change in immunostaining reflects changes in the molecular conformation of existing MAP2 caused by changes in phosphorylation state. For example, synaptic activity might stimulate increased phosphorylation of MAP2 within the microtubule binding domain, an effect that would reduce the affinity of MAP2 for microtubules (Ozer et al., 1998). This might enable molecules of MAP2 to drift or be pulled away from the activated lamina and accumulate in the adjacent dendritic zones. In addition, we cannot exclude stimulationdependent changes in the motor-driven transport of MAP2 as being partly responsible for the appearance of the trilaminar staining pattern.

Another possibility is that the synaptic activation causes a local reorganization of dendritic microstructure that is partly dependent on new protein synthesis either locally or throughout the postsynaptic neuron. In this case, the alterations in MAP2 immunostaining could be either a cause or a consequence of the dendritic reorganization or growth.

The present results add to the story that MAP2 expression can be regulated by synaptic activity. For example, previous studies have revealed decreases in MAP2 immunostaining in the visual cortex after activity over retinogeniculate pathways was blocked by injecting TTX into the eye (Hendry and Bhandari, 1992). These were seen after $5 \mathrm{~d}$ of TTX treatment and occurred selectively in the cortical columns that represent the affected eye. The present data reveal new aspects of this regulation. Specifically, the lamina-specific alterations indicate that the modifications in MAP2 can occur selectively in local dendritic domains based on the populations of synapses that are activated. Moreover, the present data indicate that the changes can occur with surprising rapidity. These findings invite the speculation that the modifications in MAP2, a key component of the dendritic cytoskeleton, may play a key role in the synaptic modifications that occur.

\section{Alterations in immunostaining for CAMKII are mediated by different processes than the alterations in MAP2}

Intense synaptic activation induced a discrete band of increased immunostaining for CAMKII in the activated lamina. This is in contrast to the pattern of immunostaining for MAP2, where there was increased immunostaining in the laminae on each side of the activated zone. This complementary pattern suggests that the 

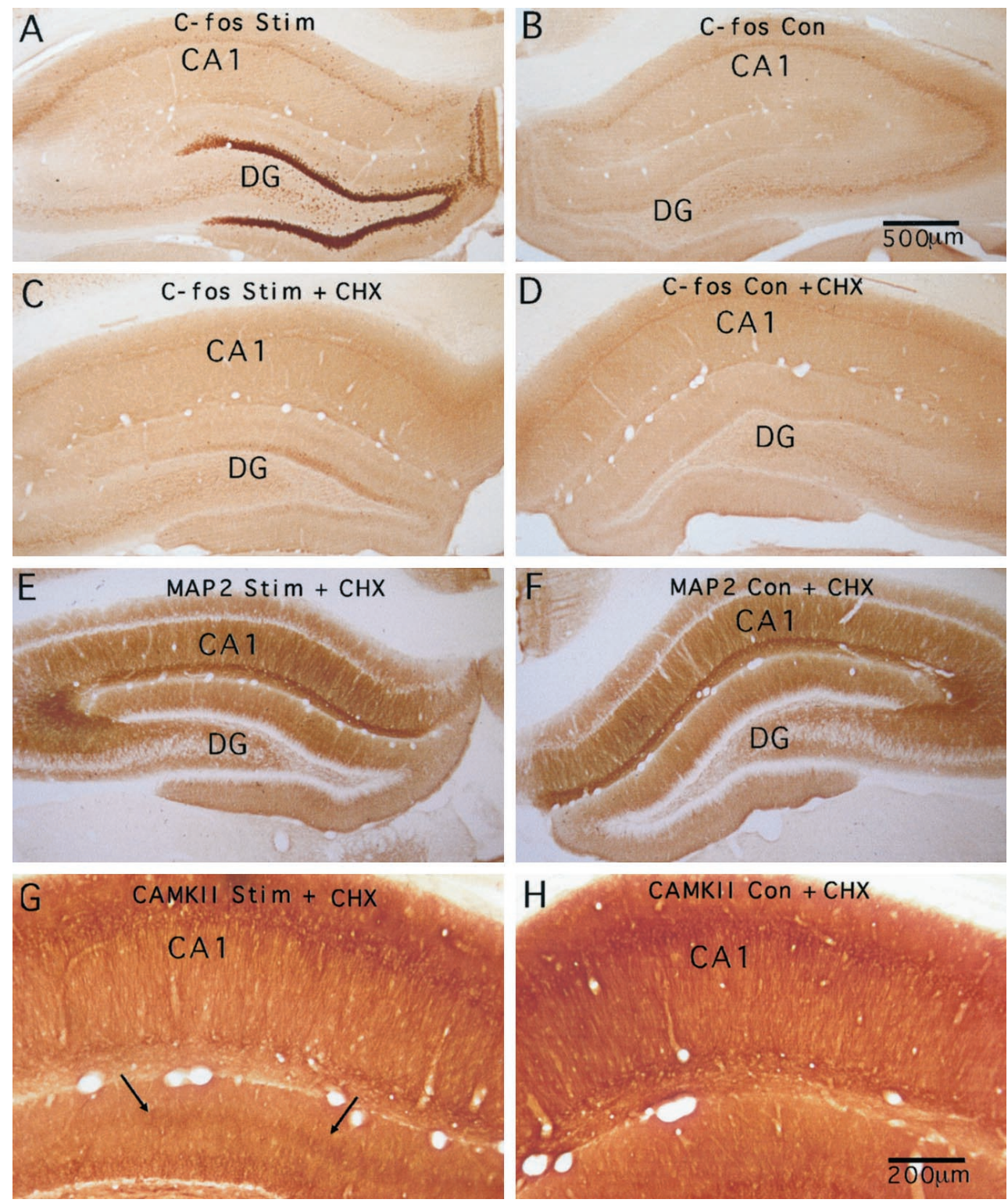

Figure 9. Systemic injections of cycloheximide block the alterations in immunostaining for MAP2 but not the increases in immunostaining for CAMKII. $A$, Induction of expression of c-fos protein after $2 \mathrm{hr}$ of high-frequency stimulation of the perforant path as revealed by immunocytochemistry (C-fos Stim). B, Pattern of immunostaining for c-fos on the control side contralateral to the stimulation. $C$ and $D$ illustrate sections from an animal that received cycloheximide $(20 \mathrm{mg} / \mathrm{kg}$, i.p.) just before the initiation of the stimulation ( $C$-fos Con). $C$, Immunostaining pattern for c-fos on the side of the stimulation $(C$-fos Stim $+\mathrm{CHX}) ; \mathrm{D}$, contralateral side $(C$-fos $C o n+C H X)$. Note that the lack of induction of c-fos protein on the stimulated side as a consequence of inhibiting protein synthesis during the stimulation period. $E$ and $F$ illustrate the immunostaining patterns for MAP2 on the stimulated and control sides of the same animal illustrated in $C$ and $D$. There is a hint of the trilaminar staining pattern in one location, but throughout most of the dentate gyrus, the pattern of MAP2 immunostaining resembles that on the nonstimulated side. $G$ and $H$ illustrate the immunostaining patterns for CAMKII on the stimulated and control sides of the same animal illustrated in $C$ and $D$. Note that the discrete band of increased staining appears comparable to what is seen in animals that did not receive protein synthesis inhibitors. changes in CAMKII immunostaining are mediated by different processes than the alterations in MAP2.

A discrete band of increased immunostaining for CAMKII in the activated lamina is expected if synaptic activation causes a local increase in CAMK II synthesis. Yet the increase was affected minimally, if at all, by inhibition of protein synthesis. This lack of sensitivity to protein synthesis inhibition is in contrast to the situation for MAP2, again suggesting that different mechanisms mediate the alterations in CAMKII versus MAP2.

The fact that protein synthesis inhibition did not block the increase in immunostaining for CAMKII suggests that mechanisms other than new protein synthesis should be considered. Possible mechanisms include those discussed above for MAP2, including conformation-dependent alterations in antibody recognition and accumulations caused by changes in CAMKII targeting or transport. Nevertheless, the conclusion that protein synthesis plays no role should be considered tentative. Immunocytochemistry is clearly subject to many variables, and it is possible that changes in protein levels are not accurately reflected by the accumulation of the immunocytochemical reaction product. For example, a ceiling effect on detection sensitivity might have masked differences in CAMKII protein levels in the protein synthesis inhibition experiments. Nevertheless, the data support the conclusion that MAP2 and CAMKII are differentially regulated in response to the patterned synaptic activation that we used in the present experiments.

It is important to emphasize that our results do not exclude the possibility that the translation of CAMKII could be regulated by other patterns of synaptic activity. In this regard, a study designed to address a similar question provided convincing evidence for increased levels of CAMKII protein in the dendritic laminae of the CA1 region following stimulation paradigms that induce LTP (Ouyang et al., 1999). Importantly, these increases were blocked by inhibiting protein synthesis. The stimulation paradigm used by Ouyang et al. (1999) was different from the one used here (in terms of pattern of stimulation), but in both cases the patterns used were the ones that are most effective for inducing LTP in the respective structures. Moreover, the stimulation paradigm that we used does lead to a dramatic accumulation of newly synthesized 
Figure 10. Local inhibition of protein synthesis blocks the alterations in immunostaining for MAP2 but not the increases in immunostaining for CAMKII. In this experiment, a recording micropipette filled with cycloheximide $(\mathrm{CHX})$ $(20 \mathrm{mg} / \mathrm{ml}$ in saline) was present on the stimulated side. $A$ illustrates the immunostaining pattern for c-fos on the stimulated side (c-fos Stim $+\mathrm{CHX})$. The diffusion of cycloheximide from the pipette produced an area several hundred micrometers in diameter in which protein synthesis was inhibited, as documented by the absence of induced expression (arrows). In areas distant from the micropipette, there was still strong induction of c-fos protein expression. $B$ illustrates the immunostaining pattern for $\mathrm{c}$-fos on the control side. $C$ illustrates the immunostaining pattern for MAP2 in the area in which protein synthesis had been inhibited $(M A P 2$ Stim $+C H X)$. The trilaminar staining pattern is much less evident than in areas distant from the site of protein synthesis inhibition. $D$ illustrates a region distant from the CHX-containing micropipette. $E$ and $F$ illustrate the immunostaining pattern for CAMKII in the area in which protein synthesis had been inhibited. Note that the discrete band of increased immunostaining appears comparable to what is seen in animals that did not receive protein synthesis inhibitors.
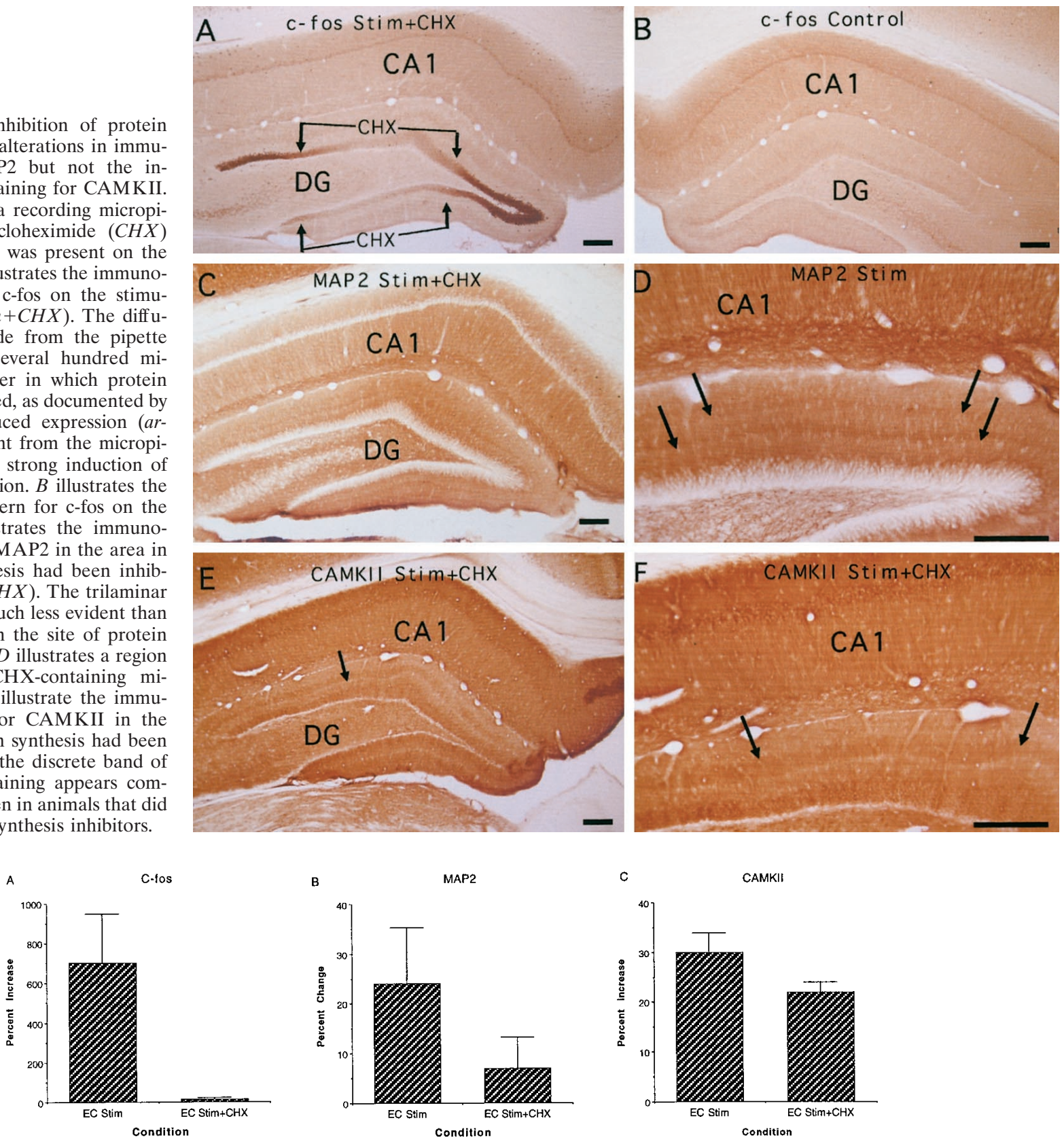

Figure 11. Quantitative assessment of the effects of local blockade of protein synthesis. To document the effects of local blockade of protein synthesis, OD measurements were taken across the molecular layer in three representative cases in which $\mathrm{CHX}$ was present in the recording micropipette. Measurements were taken at the CHX site and in a distant location. A single quantitative measure of the alteration in immunostaining was then determined as in Figure $5 C, F$, enabling us to calculate the average change in immunostaining at the site of CHX application in comparison to distant sites. $A$, The strong induction of c-fos that normally occurs as a consequence of the stimulation is completely blocked in the area near the CHX-filled micropipette. $B$, The alteration in immunostaining for MAP2 is diminished, but not eliminated, in the area near the CHX-filled micropipette. $C$, The increase in immunostaining for CAMKII is only slightly diminished in the area near the CHX-filled micropipette.

Arc mRNA and protein in the activated lamina, documenting that the activation is sufficient to dramatically modulate translation of some mRNAs. It remains to be seen whether different patterns of synaptic activation modulate CAMKII synthesis in the dendritic laminae of the dentate gyrus.

\section{Synaptic modifications in the activated and adjacent dendritic domains}

Our results, along with previous findings, document different molecular alterations in the activated and sideband laminae after intense synaptic activation. In the activated lamina, there are alterations in CAMKII and dramatic increases in newly synthesized Arc mRNA and protein. In the adjacent sideband laminae, there are increases in the level of MAP2 protein. Given this trilaminar response, it is interesting that the same pattern of stimulation used here has been shown to produce different ultrastructural modifications in the activated lamina versus the adjacent dendritic laminae in the dentate gyrus (Desmond and Levy, 1983, 1986, 1988). In the activated laminae, spine synapses had larger contact areas, and the spines assumed a U-shape, wrapping 
around the presynaptic terminal. There was actually a decrease in synapse number per unit volume. In the sideband laminae, synapses were smaller, and there was an increase in synapse number. It remains to be determined whether the immunocytochemical alterations described here are related to changes in synapse structure or number or perhaps to other changes in dendritic microstructure. In any case, the present study reveals the existence of novel mechanisms through which the molecular composition of particular dendritic regions can be differentially modified as a consequence of signals generated by synaptic activation.

\section{REFERENCES}

Berling B, Wille J, Roll B, Mandelkow E-M, Garner C, Mandelkow E (1994) Phosphorylation of microtubule-associated proteins MAP2a,b and MAP2c at Ser 136 by proline-directed kinases in vivo and in vitro. Eur J Cell Biol 64:120-130.

Desmond NL, Levy WB (1983) Synaptic correlates of associative potentiation and depression: an ultrastructural study in the hippocampus. Brain Res 265:21-30.

Desmond NL, Levy WB (1986) Changes in the numerical density of synaptic contacts with long-term potentiation in the hippocampal dentate gyrus. J Comp Neurol 253:466-475.

Desmond NL, Levy WB (1988) Anatomy of associative long-term synaptic modification. In: Long-term potentiation: from biophysics to behavior (Lanfield PW, Deadwyler S, eds), pp 265-305. New York: Liss.

Feig S, Lipton P (1993) Pairing the cholinergic agonist carbachol with patterned Schaffer collateral stimulation initiates protein synthesis in hippocampal CA1 pyramidal cell dendrites via a muscarinic, NMDAdependent mechanism. J Neurosci 13:1010-1021.

Felipo V, Grau E, Minana MD, Grisolia S (1993) Ammonia injection induces an $N$-methyl-D-aspartate receptor-mediated proteolysis of the microtubule-associated protein MAP2. J Neurochem 60:1626-1630.

Frey U, Krug M, Reymann KG, Matthies H (1988) Anisomycin, an inhibitor of protein synthesis, blocks late phases of LTP phenomena in the hippocampal CA1 region in vitro. Brain Res 452:57-65.

Hendry SHC, Bhandari,, MA (1992) Neuronal organization and plasticity in adult monkey visual cortex: immunoreactivity for microtubuleassociated protein 2. Vis Neurosci 9:445-459.

Krug M, Lossner B, Ott T (1984) Anisomycin blocks the late phase of long-term potentiation in the dentate gyrus of freely moving rats. Brain Res Bull 13:39-42.

Ouyang Y, Rosenstein A, Kreiman G, Schuman EM, Kennedy MB (1999) Tetanic stimulation leads to increased accumulation of $\mathrm{Ca}^{2+} /$ calmodulin-dependent protein kinase II via dendritic protein synthesis in hippocampal neurons. J Neurosci 19:7823-7833.

Ozer R, Batinica A, Halpain S (1998) Identification of phosphorylation sites for MAP kinase and PKA on the microtubule-associated protein MAP2. Soc Neurosci Abstr 24:2016.

Pettigrew LC, Holtz ML, Craddock SD, Minger SL, Hall N, Geddes JW (1996) Microtubular proteolysis in focal cerebral ischemia. J Cereb Blood Flow Metab 16:1189-1202.

Seubert P, Larson J, Oliver M, Jung MW, Baudry M, Lynch G (1988) Stimulation of NMDA receptors induces proteolysis of spectrin in hippocampus. Brain Res 460:189-194.

Siman R, Noszek JC (1988) Excitatory amino acids activate calpain I and induce structural protein breakdown in vivo. Neuron 1:279-287.

Steward O (1976) Topographic organization of the projections from the entorhinal area to the hippocampal formation of the rat. J Comp Neurol 167:285-314.

Steward O (1983) Polyribosomes at the base of dendritic spines of CNS neurons: their possible role in synapse construction and modification. Cold Spring Harbor Symp Quant Biol 48:745-759.

Steward O, Fass B (1983) Polyribosomes associated with dendritic spines in the denervated dentate gyrus: evidence for local regulation of protein synthesis during reinnervation. Prog Brain Res 58:131-136.

Steward O, Levy WB (1982) Preferential localization of polyribosomes under the base of dendritic spines in granule cells of the dentate gyrus. J Neurosci 2:284-291.

Steward O, Falk PM, Torre ER (1996a) Ultrastructural basis for gene expression at the synapse: synapse-associated polyribosome complexes. J Neurocytol 25:717-734.

Steward O, Kleiman R, Banker G (1996b) Subcellular localization of mRNA in neurons. In: Localized RNAs molecular biology intelligence unit series (Lipshitz HD, ed), pp 235-255. Austin, TX: R. G. Landes.

Steward O, Wallace CS, Lyford GL, Worley PF (1998) Synaptic activation causes the mRNA for the IEG arc to localize selectively near activated postsynaptic sites on dendrites. Neuron 21:741-751.

Taft WC, Yang K, Dixon CE, Hayes RL (1992) Microtubule-associated protein 2 levels decrease in hippocampus following traumatic brain injury. J Neurotrauma 9:281-290.

Wallace CS, Lyford GL, Worley PF, Steward O (1998) Differential intracellular sorting of immediate early gene mRNAs depends on signals in the mRNA sequence. J Neurosci 18:26-35.

Weiler IJ, Greenough,, WT (1993) Metabotropic glutamate receptors trigger postsynaptic protein synthesis. Proc Natl Acad Sci USA 90:7168-7171.

Weiler IJ, Irwin SA, Klintsova AY, Spencer CM, Brazelton AD, Miyashiro K, Comery TA, Patel B, Eberwine J, Greenough WT (1997) Fragile $\mathrm{X}$ mental retardation protein is translated near synapses in response to neurotransmitter activation. Proc Natl Acad Sci USA 94:5395-5400.

Wu L, Wells D, Tay J, Mendis D, Abborr M-A, Barnitt A, Quinlan E, Heynen A, Fallon JR, Richter JD (1998) CPEB-mediated cytoplasmic polyadenylation and the regulation of experience-dependent translation of alpha-CaMKII at synapses. Neuron 21:1129-1139. 